\title{
A novel double antibody sandwich-lateral flow immunoassay for the rapid and simple detection of hepatitis $\mathrm{C}$ virus
}

\author{
TINGXIU XIANG $^{1 *}$, ZHENG JIANG $^{2 *}$, JIAN ZHENG $^{4}$, CHAOYU LO $^{4}$, HARRY TSOU $^{4}$, \\ GUOSHENG REN ${ }^{2}$, JUN ZHANG ${ }^{4}$, AILONG HUANG ${ }^{3}$ and GUOQI LAI ${ }^{3}$ \\ ${ }^{1}$ Molecular Oncology and Epigenetic Laboratory, and ${ }^{2}$ Department of Gastroenterology, The First Affiliated Hospital of \\ Chongqing Medical University; ${ }^{3}$ Key Laboratory of Molecular Biology on Infectious Diseases, Ministry of Education, \\ Chongqing Medical University, Chongqing, P.R. China; ${ }^{4}$ Artron BioResearch Inc., Burnaby, BC, Canada
}

Received June 12, 2012; Accepted August 17, 2012

DOI: 10.3892/ijmm.2012.1121

\begin{abstract}
The objective of this study was to screen for antigens of the hepatitis $\mathrm{C}$ virus (HCV) to establish a new double antibody sandwich-lateral flow immunoassay (DAS-LFIA) method for testing the presence of anti-HCV antibodies in human serum or plasma. A series of different recombinant HCV proteins in Escherichia coli cells were constructed, expressed, purified and the new DAS-LFIA strip was developed. The sensitivity and specificity of new the DAS-LFIA strip were evaluated by detecting $23 \mathrm{HCV}$-positive sera, a set of quality control references for anti-HCV detection that contain known amounts of anti-HCV antibodies, and $8 \mathrm{HCV}$-negative sera. A total of 300 clinical serum samples was examined by both the new DAS-LFIA strip and enzyme-linked immunosorbent assay (ELISA). Data were analyzed using SPSS 11.5 software. The sensitivity and specificity of the new DAS-LFIA strip were $100 \%$. The lowest test line of the HCV DAS-LFIA strips was $2 \mathrm{NCU} / \mathrm{ml}$. Additionally, the concordance between the new DAS-LFIA strip and ELISA methods was $94.33 \%$. In conclusion, our new testing method is rapid, simple, sensitive and specifically detects the presence of anti-HCV antibodies in human serum or plasma. Therefore, it may be used for monitoring $\mathrm{HCV}$.
\end{abstract}

\section{Introduction}

It is estimated that approximately 180 million people have been infected with the hepatitis $\mathrm{C}$ virus (HCV) and approximately 130 million people are chronic HCV carriers (1).

Correspondence to: Dr Guoqi Lai, Key Laboratory of Molecular Biology on Infectious Diseases, Ministry of Education, Chongqing Medical University, 1 Yixueyuan Road, Chongqing 400016, P.R.China E-mail: a68895078@21cn.com

*Contributed equally

Key words: hepatitis $\mathrm{C}$ virus, recombinant protein, double antibody sandwich-lateral flow immunoassay, colloidal gold
$\mathrm{HCV}$ is a common cause of chronic hepatitis, cirrhosis and hepatocellular carcinoma worldwide (2-4). Currently, there are two main methods for detecting an HCV infection: one detects viral RNA by RT-PCR (5-8) and the other detects HCV antibodies by immunoassay [enzyme-linked immunosorbent assay (ELISA)] in serum $(9,10)$. The sensitive ELISA assay uses recombinant viral proteins corresponding to multiple polypeptides from different viral regions, including structural proteins and non-structural polypeptides (11-13). It can be used as a confirmation test. However, its usage is limited in the clinical setting as the procedure requires sophisticated laboratory equipment and there is a high probability of contamination. Therefore, the purpose of our study was to develop an affordable and reliable rapid lateral flow test to detect the presence of HCV antibodies in blood samples by screening for HCV antigens, which would help decrease the chances of $\mathrm{HCV}$ infection from blood transfusions.

\section{Materials and methods}

Plasmids and bacterial strains. The p90/HCVFLlongpU plasmid carrying full-length coding sequences of HCV was a generous gift from Professor Charles M. Rice from the Center for the Study of Hepatitis C, Rockefeller University, New York, NY, USA. The Escherichia coli (E. coli) strains, Jm109, DH5a and BL21 (DE3), were used as the cloning and expression hosts.

Reagents and instruments. A panel of 23 standard positive sera, 8 standard negative sera, a set of quality control references for anti-HCV detection that contain known amounts of anti-HCV antibodies (Artron BioResearch Inc., Burnaby, BC, Canada) and 300 clinical sera were used for the antigenicity assessment of HCV proteins. Other reagents and instruments included goat anti-mouse HCV IgG polyclonal antibody, 30-60 nm colloidal gold particles (from Artron BioResearch Inc.), HCV-ELISA (KHB, Shanghai, China), a NanoDrop ${ }^{\circledR}$ ND-1000 Spectrophotometer, a Bio-Rad BioLogic LP, ZQ4000 test strip cutter, and XYZ-3000 Bio-Dot (all from Bio-Rad, Shanghai, China).

Construction and expression of recombinant HCV antigens. To obtain the HCV antigens, the sequences encoding the desired 
regions in the HCV genome were amplified by RT-PCR, and cloned into the prokaryotic expression vectors, pQE30 (Qiagen, Hilden, Germany), pET32a(+) (Novagen, Darmstadt, Germany), or pGEX-4T-2 (GE Healthcare Life Sciences, Chalfont St. Giles, $\mathrm{UK}$ ), in-frame downstream of the 6-His-tag or glutathione S-transferase (GST)-tag coding sequence. Primers used for the HCV PCR amplification are listed in Table I and the structures of the plasmids are illustrated in Fig. 1.E. coli BL21 (DE3) cells harbouring the $\mathrm{HCV}$ gene fragment were grown at $37^{\circ} \mathrm{C}$ in $\mathrm{LB}$ medium containing $50 \mu \mathrm{g} / \mathrm{ml}$ of ampicillin to $\mathrm{OD}_{600}=0.8$. The expression of the antigens was induced by adding isopropyl$\beta$-D-thiogalactopyranoside (IPTG) to a final concentration of $1 \mathrm{mmol} / \mathrm{l}$. The cells were harvested $4-6 \mathrm{~h}$ later by centrifugation at $10,000 \mathrm{rpm}$ for $15 \mathrm{~min}$ and stored at $-20^{\circ} \mathrm{C}$. Solubility analyses of expression products were performed as previously described (14). Briefly, harvested bacteria were re-suspended in phosphate-buffered saline (PBS; containing $140 \mathrm{mmol} / \mathrm{l} \mathrm{NaCl}$, $2.7 \mathrm{mmol} / 1 \mathrm{KCl}, 10 \mathrm{mmol} / 1 \mathrm{Na}_{2} \mathrm{HPO}_{4}, 1.8 \mathrm{mmol} / 1 \mathrm{KH}_{2} \mathrm{PO}_{4}$, $\mathrm{pH} 7.3$ ), sonicated on an ice-bath, and centrifuged at $10,000 \mathrm{rpm}$ for $20 \mathrm{~min}$ at $4^{\circ} \mathrm{C}$. After centrifugation, the soluble and insoluble fractions were analyzed for the presence of expression products.

Purification of recombinant $H C V$ antigens. To purify the expressed proteins, we chose to use a Ni-nitrilotriacetic acid (Ni-NTA) affinity chromatography column for His-tagged proteins and a glutathione sepharose ${ }^{\mathrm{TM}} 4 \mathrm{~B}$ column for GST-tagged proteins. The two methods are similar as regards experimental procedures but differ in column chromatography and reagents, as described below:

i) Protein purification with Ni-NTA column. The column was first equilibrated with lysis buffer $\left(50 \mathrm{mM} \mathrm{NaH}{ }_{2} \mathrm{PO}_{4}\right.$, $300 \mathrm{mM} \mathrm{NaCl}, 10 \mathrm{mM}$ imidazole, $\mathrm{pH}$ 7.8) at five times the volume of the beads. The sample was then loaded and allowed to flow slowly in order to maximize the amount of protein bound to the beads. The flow-through solution was collected for SDS-PAGE analysis later. After the sample was completely loaded, washing buffer $\left(50 \mathrm{mM} \mathrm{NaH} \mathrm{PO}_{4}, 300 \mathrm{mM} \mathrm{NaCl}\right.$, $20 \mathrm{mM}$ imidazole, $\mathrm{pH}$ 8.0) was added to wash off unspecific proteins bound to the beads or remaining in the column until the $\mathrm{OD}_{280}$ reading was below 0.100 . The proteins of interest were eluted by adding elution buffer $\left(50 \mathrm{mM} \mathrm{NaH} \mathrm{PO}_{4}\right.$, $300 \mathrm{mM} \mathrm{NaCl}, 250 \mathrm{mM}$ imidazole, $\mathrm{pH}$ 8.0).

ii) Protein purification with glutathione sepharose $4 B$ column. The general procedures were the same as those for the Ni-NTA columns, although the buffers used in the GST columns were different. PBS solution ( $\mathrm{pH} 7.4)$ was used for equilibration. After the sample was loaded, the same PBS solution was used to wash the column. Finally, the glutathione solution (50 mM Tris-HCL, $10 \mathrm{mM}$ reduced glutathione) was used to elute the protein of interest. All purified recombinant HCV antigens were found to be $>90 \%$ pure based on SDS/polyacrylamide gel analysis followed by Coomassie blue staining. Eluents with high $\mathrm{OD}_{280}$ were collected into a membrane bag and dialysis was performed overnight at $4^{\circ} \mathrm{C}$ in a buffer (PBS buffer). Protein concentration was measured using the Bradford method with bovine serum albumin as the standard.

Construction of double antigen sandwich-lateral flow immunoassay (DAS-LFIA) strip and indirect lateral flow immunoassay
(I-LFIA). The DAS-LFIA device for the detection of anti-HCV antibodies was manufactured by Artron BioResearch Inc. First, we optimized the conditions for the colloidal gold conjugation of the purified antigen and the coating of the gold-conjugated recombinant protein on non-woven fabric sheets. Colloidal gold is used as an indicator for the presence of antigens binding to the membrane on the rapid lateral flow test strip. After the proteins are bound to colloidal gold to form the conjugate, the fabric sheets are placed in a dry room for at least $2 \mathrm{~h}$ for drying. Subsequently, the purified antigen, diluted in PBS, is coated on the test region. Simultaneously, HCV IgG polyclonal antibody, diluted in PBS, is coated on the control region. The coated membrane is dried for a minimum of $24 \mathrm{~h}$ and then blocked with a particular blocking solution. Finally, the test strip is assembled such that everything slightly overlaps in order to allow for the continuous lateral flow of the liquid sample. The test strip has an absorption pad, a strip of membrane, a conjugate fibre and other fibres to hold the conjugate fibre in place. Instructions on how to assemble a test strip were provided by Artron BioResearch Inc. The combination of the coating protein, conjugate protein, conjugate fibre and dialysis buffer forms a 'system' in a test strip. The test strip developed was tested with different positive and negative HCV sera. I-LFIA was manufactured using IgG antibody conjugating colloidal gold instead of antigen.

Test principle and assay procedure. Each test solution $(50 \mu \mathrm{l})$ was pipetted onto the sample pad and driven to migrate by capillary action along the strip. If $\mathrm{HCV}$ antibodies were present in the serum or plasma, they would react with the colloidal goldconjugated antigen to form an antibody-antigen complex. This complex would flow through the absorbent device and bind to the antigen in the positive reaction test zone (' $\mathrm{T}$ ' area), forming a gold-conjugated Ag-Ab-Ag sandwich complex, producing a pink-purple colored band. A colored band in the control region of the device indicates adequate sample volume and capillary action. The absence of a colored band in the control region is an indication of an invalid result. Positive results were read as soon as two colored bands appeared. Negative samples provided only one pink control band. If no control band was present, the test was considered invalid. Color formation for both reactions was complete after 5-10 min. A schematic representation of possible test results is shown in Fig. $2 \mathrm{~B}$.

Determination of sensitivity and specificity of the $\mathrm{HCV}$ strip. To assess the sensitivity of the HCV strip, a panel of 23 standard positive sera were simultaneously measured by the ELISA, DAS-LFIA, I-LFIA and RT-PCR methods. In addition, serial dilutions of a reference panel with known amounts of anti-HCV antibodies with a concentration from $8 \mathrm{NCU} / \mathrm{ml}$ (NCU meaning national clinical unit) to $0.5 \mathrm{NCU} / \mathrm{ml}$ were measured by the DAS-LFIA strip. To assess the specificity and accuracy the $\mathrm{ddH}_{2} \mathrm{O}$, positive enhancement sample (a set of quality control references for anti-HCV antibody detection that contains known amounts of anti-HCV antibodies; Artron BioResearch Inc.), BS control and $8 \mathrm{HCV}$-negative patients were analyzed by the DAS-LFIA strip.

Detection of HCV antibodies in clinical specimens. A total of 300 clinical samples was analyzed by the new DAS-LFIA 
Table I. Sequences of oligonucleotide primers that were used to validate the expression of several different HCV segment genes.

\begin{tabular}{|c|c|c|c|}
\hline No. & Primer sequences & Primary description & Enzyme site \\
\hline F1 & 5'-CGGGATCCATGAGCACGAATCCTAAACC-3' & Core-190 & Bam $\mathrm{HI}$ \\
\hline $\mathrm{R} 1$ & 5'-TTAAGCTTCTGAAGCGGGCACAGTC-3' & & HindIII \\
\hline $\mathrm{F} 2$ & 5'-CGGGTACCATGAGCACGAATCCTAAAC-3' & Core-68 & Kpn I \\
\hline R2 & 5'-TTGGATCCACGTGCCTTGGGGATA-3' & & BamHI \\
\hline F3 & 5'-CGGGTACCACGCAAGACTGCAATTGTT-3' & E1 300-407 & KpnI \\
\hline R3 & 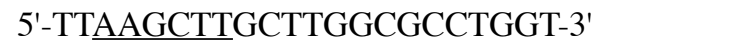 & & HindIII \\
\hline $\mathrm{F} 4$ & 5'-CGGGATCCTACCAAGTGCGCAATTC-3' & E1 192-318 & BamHI \\
\hline R4 & 5'-CGAAGCTTATGCCATGCGATGACC-3' & & HindIII \\
\hline F5 & 5'-AAGGATCCACACCAGGCGCCAAG-3' & E2 403-642 & BamHI \\
\hline R5 & 5'-TTEAATTCCGCTTCCAGCCTGTG-3' & & EcoRI \\
\hline F6 & 5'-CCGGTACCTTGGAGAACCTCGTAAT-3' & P7 747-807 & $K p n \mathrm{I}$ \\
\hline R6 & 5'-TGGAATTCGTATGCCCGCTGAG-3' & & EcoRI \\
\hline F7 & 5'-TTGGTACCTGTGGCGGCGTTGTT-3' & NS2 817-1022 & $K p n \mathrm{I}$ \\
\hline R7 & 5'-CGGAATTCCCACCCCTTGGAGACCAT-3' & & EcoRI \\
\hline F8 & 5'-TTGGTACCCAGACGAGAGGCCTCCTAG-3' & NS3 1034-1193 & $K p n \mathrm{I}$ \\
\hline R8 & 5'-TTGGATCCGTCCACCGCCTTAGCC-3' & & BamHI \\
\hline F9 & 5'-AAGGATCCGTGTGCACCCGTGGAGT-3' & NS3 1183-1476 & BamHI \\
\hline R9 & 5'-GGAAGCTTGGAGCGTGGTTGTCTCAAT-3' & & HindIII \\
\hline F10 & 5'-CCGAATTCTTCAGCCTTGACCCTAC-3' & NS3 1463-1656 & EcoRI \\
\hline R10 & 5'-TTAAGCTTGCGTGACGACCTCC-3' & & HindIII \\
\hline F11 & 5'-TTGGTACCGTCCTGGCTGCTCTG-3' & NS4A $1665-1710$ & Kpn I \\
\hline R11 & 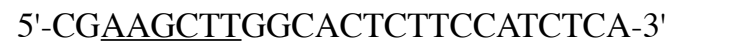 & & HindIII \\
\hline F12 & 5'-TTGGTACCCCTGGAGCCCTTGTAGT-3' & NS4B 1888-1937 & Kpn I \\
\hline R12 & 5'-TTGAATTCGCTCTCCGGCACGTAG-3' & & EcoRI \\
\hline F13 & 5'-AAGGTACCGCAGAGGAGGATGAGC-3' & NS5A 2258-2419 & KpnI \\
\hline R13 & 5'-CGGAATTCGCAGCACACGACATCTT-3' & & EcoRI \\
\hline F14 & 5'-TTGGTACCTGGACAGGCGCACTCGT-3' & NS5B 2425-2733 & KpnI \\
\hline R14 & 5'-TTGTCGACCGAGCATGGTGCAGTCC-3' & & SalI \\
\hline
\end{tabular}

F, forward primer; R, reverse primer. HCV, hepatitis C virus. The underlined sequences show the base sequences of the enzyme sites.

method as described above and the HCV ELISA test kit (Shanghai Huaguan Biochip Co., Ltd.) according to the supplier's instructions.

Statistical analysis. The statistical package SPSS 11.5 was used for data analysis. P-value $\leq 0.05$ was considered to indicate a statistically significant difference.

\section{Results}

Construction of expression plasmids. For the expression of $\mathrm{HCV}$ proteins in E. coli, corresponding coding sequences were cloned into the histidine fusion expression vectors, pET32a(+) and pQE30, or the GST-tag expression vector, pGEX-4T-2, as shown in Table I and Fig. 1. Recombinant plasmids were examined and confirmed by PCR amplification, restriction enzyme digestion and DNA sequencing. We successfully produced a set of recombinant proteins derived from $\mathrm{HCV}$ structural (core, E1 and E2) and non-structural proteins (NS2,
NS3, NS4A, NS4B, NS5A and NS5B) in BL21 (DE3) cells by using the $E$. coli expression system.

Expression and purification of recombinant $H C V$ proteins. In order to obtain pure proteins, recombinant plasmids were used to transform E. coli BL21 (DE3) cells and expression was induced with $1 \mathrm{mM}$ IPTG. The expressed proteins were purified with $\mathrm{Ni}^{2+}$-chelate affinity chromatography and a glutathione sepharose $\mathrm{e}^{\mathrm{TM}} 4 \mathrm{~B}$ column. Proteins were examined using SDS-PAGE (Fig. 3). The position of the protein bands was consistent with the expected molecular weight of the different HCV segments. Protein concentration was determined by the BCA method, using BSA as the standard. Our further analyses demonstrated that the $\mathrm{HCV}$ proteins were pure and that they could be used directly for the construction of the HCV DAS-LFIA strip.

Analytical parameters of the optimized one-step strip. In the current study, we optimized the concentration of the coating 


A
5'UTR
\begin{tabular}{|c|c|c|c|c|c|c|c|c|c|}
\hline core & E1 & E2 & P7 & NS2 & NS3 & NS4a & NS4b & NS5a & NS5b \\
\hline $1-191$ & $192-383$ & $384-746$ & & $809-1026$ & $1027-1657$ & & $1711-1972$ & $1973-2420$ & $2421-3012$ \\
\hline
\end{tabular}

\section{B}

(EET-Core68
pET-Core190 (core1-68aa)
pET-NS2
pET-NS3-1
pET-NS3-2
pET-C33
pET-NS4A

pET-NS4B
pET-NS5A (core1-120aa)
pET-NS5B (core1-190aa)
pQE-C22 (NS4531183-1476aa)
pQE-Core190
pQE-NS3-2
pQE-C33 (NS31192-1457aa)
pGEX-Core68
pGEX-Core190 (core1-190aa)
pGEX-C22
pGST-NS3

Figure 1. HCV genome and recombinant proteins. (A) The HCV genome contains a single major open reading frame (ORF) flanked by untranslated regions (UTRs). The 10 proteins encoded within the main ORF are indicated by alternated shading. (B) Genomic fragments of HCV were cloned into the prokaryotic expression vectors, pET32a(+), pQE30, or pGEX-4T-2, in-frame downstream of the 6-His-tag or glutathione S-transferase (GST)-tag coding sequence.

A

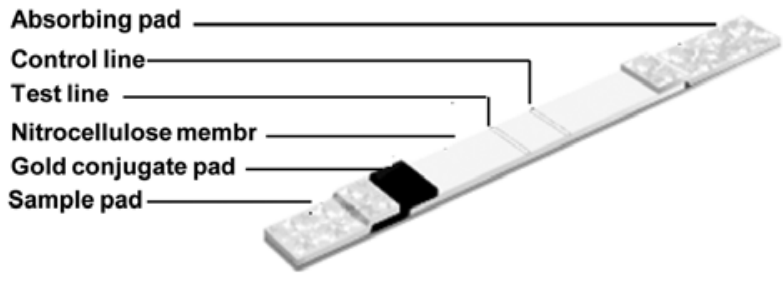

B

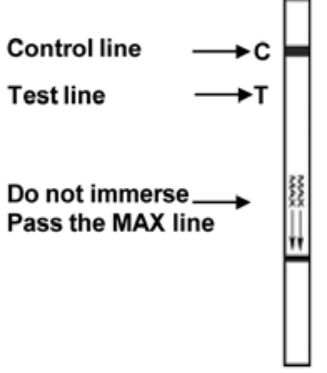

Negative

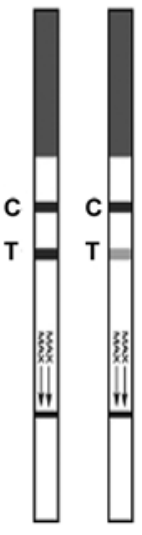

Positive

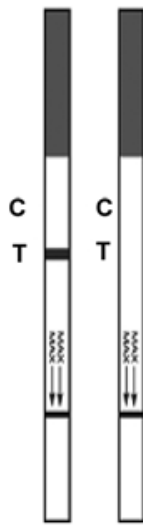

Invalid

Figure 2. (A) Schematic diagram of a colloidal gold-based DAS-LFIA strip. The strip is composed of a sample pad, a conjugate pad that contains the core combined with NS3 (1183-1947 aa) for double antigen sandwich LFIA and antibody for indirect LFIA, and an absorbent pad attached to a nitrocellulose membrane, with a test line and an IgG control line impregnated onto the surface of the membrane. (B) Representative results of LFIA with serum. T, test line is present for samples with HCV antibody and absent for samples without HCV antibody; C, control line shows a normal flow of the liquid through the strip. Two lines indicate a positive result and one line indicates a negative result.

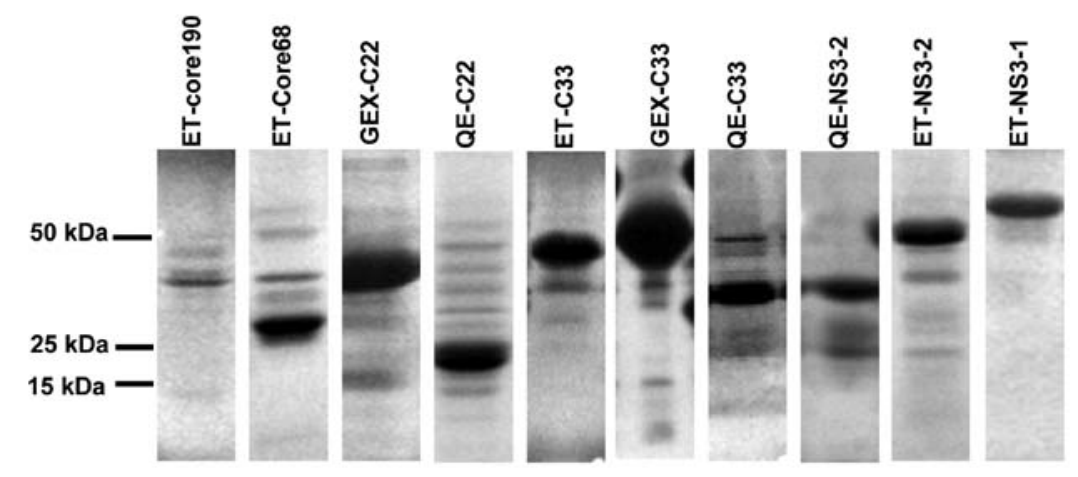

Figure 3. SDS-PAGE analysis of purified recombinant HCV proteins. Individual HCV genes were inserted into the His-tag or GST-tag expression plasmids. Recombinant HCV proteins were produced in BL21 (DE3) cells and purified. Samples of purified HCV proteins were separated by 10-12\% SDS-PAGE and stained with Coomassie blue. 
Table II. Specification of materials and parameters of the optimized DAS-LFIA strip.

\begin{tabular}{|c|c|}
\hline Item & Specification \\
\hline Membrane & $\begin{array}{l}\text { High-flow NC membrane; thickness, } 140 \mu \mathrm{m} \pm 20 \% \text {; } \\
\text { absorption: speed, } \geq 10 \mathrm{~mm} / \mathrm{min} \text {; size of the pore, } 5-15 \mu \mathrm{m}\end{array}$ \\
\hline Fiber glass & Absorbent cotton: thickness, $0.3-0.5 \mathrm{~mm}$; intensity, $50 \pm 5 \mathrm{~g} / \mathrm{m}^{2}$ \\
\hline Absorbent paper & Absorbent cotton: thickness, $0.6-0.8 \mathrm{~mm}$; intensity, $270 \pm 20 \mathrm{~g} / \mathrm{m}^{2}$ \\
\hline Colloidal gold & Particle size, $30-60 \mathrm{~nm}$ \\
\hline Coating buffer & Tris-HCL buffer $\mathrm{pH} 8.0$ \\
\hline Coating concentration & $1 \mathrm{mg} / \mathrm{ml}$ \\
\hline
\end{tabular}

DAS-LFIA, double antigen sandwich-lateral flow immunoassay; NC membrane, nitrocellulose membrane.

Table III. Results of the positive rates of anti-HCV antibodies detected by the DAS-LFIA strip and the other methods.

\begin{tabular}{ll}
\hline Tests & Positive rate $(\%)$ \\
\hline ELISA (KHB) & $(22 / 23) 95.65$ \\
DAS-LFIA (core and NS 1183-1476 aa) & $(23 / 23) 100$ \\
I-LFIA (core and NS 1183-1476 aa) & $(22 / 23) 95.65$ \\
I-LFIA (core) & $(22 / 23) 95.65$ \\
I-LFIA (NS3 1183-1476 aa) & $(22 / 23) 95.65$ \\
I-LFIA (NS3 1192-1457 aa) & $(20 / 23) 86.95$ \\
RT-PCR & $(23 / 23) 100$
\end{tabular}

ELISA, enzyme-linked immunosorbent assay; DAS-LFIA, double antigen sandwich-lateral flow immunoassay; I, indirect; HCV, hepatitis $\mathrm{C}$ virus; aa, amino acid.

antigen, the amount of colloidal gold-labelled antigen on the conjugate pad, the characteristics of the materials used, the buffer systems, the additives, and the solvents applied to ensure that the assays ran successfully over the concentration range required (Table II).

Sensitivity and specificity of HCV DAS-LFIA strip including core and a new NS3 recombinant protein. The purified proteins would be used to determine whether they have a prognostic value in patients suffering from chronic $\mathrm{HCV}$ infection. Of the 23 standard positive sera (derived from confirmed HCV RNA and antibody-positive patients), 95.6\% recognized the core and $95.6 \%$ recognized the NS3 protein. The remaining HCV proteins were very poorly immunogenic. Only three serum specimens recognized the NS5B protein and none of the sera recognized the NS2 protein.The results showed that the core and NS3 [1183-1476 amino acids (aa)] of the HCV polyprotein had strong positive reactions to positive sera. However, the core and NS3 (1183-1476 aa) each had one false-negative result when testing the positive control samples. Thus, we combined the core and NS3 (1183-1476 aa) as the coating antigen of the new DAS-LFIA strip. Our data suggested that
Table IV. Lowest test limit for a positive human anti-HCV antibody detected by the DAS-LFIA strip.

\begin{tabular}{lc}
\hline $\begin{array}{l}\text { Human anti-HCV antibody } \\
\text { concentration (NCU/ml) }\end{array}$ & LFIA result \\
\hline 8 & Positive \\
4 & Positive \\
2 & Positive \\
1 & Negative \\
0.5 & Negative
\end{tabular}

DAS-LFIA, double antigen sandwich-lateral flow immunoassay; $\mathrm{HCV}$, hepatitis $\mathrm{C}$ virus.

the new DAS-LFIA strip was able to detect HCV antibodies at high positive rates $(100 \%)$ when compared with the ELISA, I-LFIA and RT-PCR methods using the same serum samples (Table III) $(\mathrm{P}>0.05)$. In this model of HCV infection, the test line of the anti-HCV DAS-LFIA strip was $2 \mathrm{NCU} / \mathrm{ml}$ (Table IV). All antigens ran against negative samples did not show any signs of reactivity in comparison to the control test strip (Fig. 4). This indicated that the HCV antigen did not cross-react with other common viral antibodies and thus, was highly specific to HCV.

Immunoassay of the 300 clinical specimens. A total of 300 samples was measured using the anti-HCV DAS-LFIA strip and anti-HCV ELISA immunoassays. In these 300 cases, we found that the rate of the anti-HCV DAS-LFIA strip and the ELISA-negative one was $78 \%$ (234/300). The rate of anti-HCV DAS-LFIA-negative but ELISA-positive was $2 \%$ (6/300). The rate of the anti-HCV DAS-LFIA-positive strip but the ELISAnegative one was $3.67 \%$ (11/300). The rate of the anti-HCV DAS-LFIA and ELISA-positive was $16.33 \%$ (49/300). The concordance between the ELISA and DAS-LFIA methods was $94.33 \%$. The disagreement rate between the ELISA and DAS-LFIA methods was not significant $\left(\chi^{2}=0.941, \mathrm{P}=0.332\right)$ (Table V). 


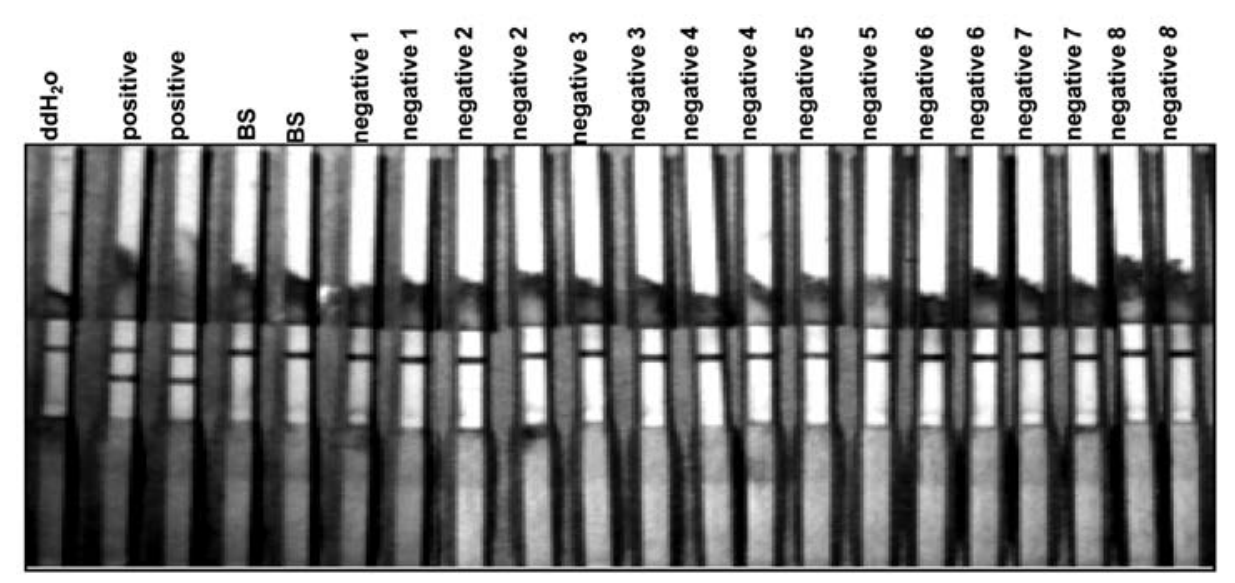

Figure 4. Determination of specificity of the DAS-LFIA strip.

Table V. Results from 300 plasma donor samples detected by the DAS-LFIA strip and HCV ELISA assay.

\begin{tabular}{lccr}
\hline & \multicolumn{3}{c}{ HCV ELISA } \\
\cline { 2 - 4 } DAS-LFIA & Negative & Positive & Total \\
\hline Negative & 234 & 6 & 240 \\
Positive & 11 & 49 & 60 \\
Total & 245 & 55 & 300 \\
\hline
\end{tabular}

$\chi^{2}=0.941176, P>0.05$. DAS-LFIA, double antigen sandwich-lateral flow immunoassay.

\section{Discussion}

In this present study, we characterized the immunoreactivity of recombinant $\mathrm{HCV}$ polypeptides derived from many different regions of the $\mathrm{HCV}$ polyprotein expressed in bacteria. The purpose of synthesizing these segments is to determine which segments encoded by the genome are significant for the development of anti-HCV assays and to find a multiple epitope fusion antigen which incorporates all of the major immunodominant epitopes from the functional regions of the $\mathrm{HCV}$ genome. Therefore, we first constructed the different $\mathrm{HCV}$ segments into vectors containing His-tag or GST-tag to induce expression. The proteins were expressed in BL21 (DE3) cells as fusion proteins with a $26 \mathrm{kDa}$ GST-tag or $18 \mathrm{kDa}$ His-tag used for detection and affinity purification. The immunogenicity of the tagged fusion proteins was analyzed using HCV strip analysis with standard positive and negative anti-HCV sera. Our results showed that the recombinant soluble proteins were expressed successfully. The sera studied recognized the core and NS3 protein at very high levels, whereas the other proteins, such as NS4B, NS4A, NS5A and NS5B, were found to have lower levels of reactivity. The $\mathrm{E} 2$ protein rarely reacted with antiHCV positive serum. Thus, the core protein in combination with a new NS3 protein (1183-1476 aa) constitutes almost all of the major immunogenic proteins of the HCV. However, this study does not exclude the possibility that the low reactivity to some $\mathrm{HCV}$ antigens is due to a quantitative reduction in the titer of antibodies and not due to an absence of reactivity.

To determine the contributions of various regions of the core protein and NS3 protein to infectivity diagnosis, clones of the core gene and different NS3 segments were expressed in E. coli cells and the recombinant proteins were used to test human antiHCV-positive sera in the ELISA and the rapid lateral flow test strip. The data suggested that the full-length core protein and the new NS3 protein (1183-1476 aa) were suitable for analyzing the presence of antibodies against individual $\mathrm{HCV}$ proteins in human sera obtained from patients suffering from chronic $\mathrm{HCV}$ infection. These results are in agreement with those of previous studies in which the putative nucleocapsid protein (C) and non-structural proteins (NS3) were found to contain the most immunodominant epitopes (15-19).

Several studies have indicated that a peptide spanning aa 2-120 of the $C$ gene (C22) is a major component of the commercially available second-generation anti-HCV tests. Our study demonstrates that the full-length core protein has better reactivity than $\mathrm{C} 22$. It is possible that the $\mathrm{C}$-terminal domain of the core protein contains key peptide sequences for constructing the viral particle and regulating viral assembly $(4,20)$.

The HCV NS3 protein is composed of an amino terminal protease and a carboxyl terminal RNA helicase (21). NS3 contains major antigenic epitopes and plays an important role in the diagnosis of $\mathrm{HCV}$ infection, particularly in early HCV infection (21). In this study, to our knowledge, our results demonstrate for the first time that a new NS3 segment (1183-1476 aa) shows strong reactivity in 95.6\% of RT-PCRpositive samples and can act as a potential tool for the diagnosis of HCV infection.

To achieve the greatest possible sensitivity and specificity, we chose two formats of gold-based immunoassays. In the double antigen sandwich immunoassay, the HCV antigen labelled with colloidal gold is a soluble recombinant antigen. During the test, $\mathrm{HCV}$ antibodies in the sample react with antigen coated on the nitrocellucose membrane and gold-HCV antigen conjugates, forming a gold-conjugated $\mathrm{Ag}-\mathrm{Ab}-\mathrm{Ag}$ sandwich complex. At the same time, we carried out a series of experiments to optimize different parameters, such as the amount of immunoreagents, the type of materials, and the composition of the blocking solution and detector reagent mixture. The experimental results demon- 
strated that the chromatographic strip device we constructed is simple, sensitive and specific. It is an ideal test for the screening of patients with HCV infection. The presence of recombinant core and NS3 antigens in the strip may be crucial for the detection of $\mathrm{HCV}$-infected patients with low antibody titers.

In conclusion, we found that recombinant antigens encoded by different HCV gene fragments display different immunoreactivity to anti-HCV antibodies. Our data show the full-length core and NS3 (1183-1476 aa) proteins have the major immunodominant epitopes of the HCV genome. More importantly, our study verify that the full-length core and NS3 (1183-1476 aa) recombinant antigen can be used to construct a double antigen sandwich lateral-flow immunochromatographic anti-HCV immunoassay strip. This strip allows for the more rapid and more economical detection of HCV. It also has a high sensitivity and specificity in testing for HCV. It has the potential to become a useful tool for HCV clinical detection.

\section{Acknowledgements}

This study was financially supported by Artron BioResearch Inc. and the Chongqing Natural Science Foundation (\#CSTC, 2010AB5012). The authors would like to thank Dr XueFei Cai (Chongqing Medical University) for providing pET-C33 and pET-C22.

\section{References}

1. Nakamura J, Terajima K, Aoyagi Y and Akazawa K: Costeffectiveness of the national screening program for hepatitis $\mathrm{C}$ virus in the general population and the high-risk groups. Tohoku J Exp Med 215: 33-42, 2008.

2. Belloni L, Moretti F, Merlo P, et al: DNp73alpha protects myogenic cells from apoptosis. Oncogene 25: 3606-3612, 2006.

3. Schuppan D, Krebs A, Bauer M and Hahn EG: Hepatitis C and liver fibrosis. Cell Death Differ 10 (Suppl 1): S59-S67, 2003.

4. Luo JC, Hwang SJ, Li CP, et al: Clinical significance of serum auto-antibodies in Chinese patients with chronic hepatitis $\mathrm{C}$ : negative role of serum viral titre and genotype. J Gastroenterol Hepatol 13: 475-479, 1998.

5. Schroeter M, Zoellner B, Polywka S, Laufs R and Feucht HH: Prolonged time until seroconversion among hemodialysis patients: the need for HCV PCR. Intervirology 48: 213-215, 2005.

6. Zaaijer HL, Cuypers HT, Reesink HW, Winkel IN, Gerken G and Lelie PN: Reliability of polymerase chain reaction for detection of hepatitis C virus. Lancet 341: 722-724, 1993.
7. Shahzamani K, Sabahi F, Merat S, et al: Rapid low-cost detection of hepatitis C virus RNA in HCV-infected patients by real-time RT-PCR using SYBR Green I. Arch Iran Med 14: 396-400, 2011.

8. Machnik G, Pelc E, Zapala M, et al: Designing and optimization of real-time RT-PCR technique for the detection of hepatitis $C$ virus (HCV) genome in blood serum as internal laboratory quality control. Przegl Epidemiol 65: 325-332, 2011 (In Polish).

9. Gao Q, Liu D, Zhang S and Tong L: Analyses of anti-hCV detected by ELISA and HCV RNA detected by RT-nPCR in chronic hepatitis C virus infectors. Wei Sheng Yan Jiu 36: 69-71, 2007 (In Chinese).

10. Reddy AK, Dakshinamurty KV and Lakshmi V: Utility of $\mathrm{HCV}$ core antigen ELISA in the screening for hepatitis $\mathrm{C}$ virus infection in patients on hemodialysis. Indian J Med Microbiol 24: 55-57, 2006.

11. Rios M, Diago M, Rivera P, et al: Epidemiological, biological and histological characterization of patients with indeterminate third-generation recombinant immunoblot assay antibody results for hepatitis C virus. J Viral Hepat 13: 177-181, 2006.

12. Tung HD, Lu SN, Lee CM, et al: Antiviral treatment responses in patients with chronic hepatitis $\mathrm{C}$ virus infection evaluated by a third generation anti-hepatitis $\mathrm{C}$ virus assay. J Viral Hepat 9: 304-308, 2002

13. Sookoian S and Castano G: Evaluation of a third generation anti-HCV assay in predicting viremia in patients with positive HCV antibodies. Ann Hepatol 1: 179-182, 2002.

14. Zhang J, Wang D, Li Y, et al: SARS coronavirus nucleocapsid protein monoclonal antibodies developed using a prokaryotic expressed protein. Hybridoma (Larchmt) 30: 481-485, 2011.

15. Goeser T, Muller HM, Ye J, Pfaff E and Theilmann L: Characterization of antigenic determinants in the core antigen of the hepatitis C virus. Virology 205: 462-469, 1994.

16. Beld M, Penning M, van Putten M, et al: Quantitative antibody responses to structural (Core) and nonstructural (NS3, NS4, and NS5) hepatitis $\mathrm{C}$ virus proteins among seroconverting injecting drug users: impact of epitope variation and relationship to detection of HCV RNA in blood. Hepatology 29: 1288-1298, 1999.

17. Hwang SJ: Hepatitis C virus infection: an overview. J Microbiol Immunol Infect 34: 227-234, 2001.

18. Nikolaeva LI, Blokhina NP, Tsurikova NN, et al: Virus-specific antibody titres in different phases of hepatitis $\mathrm{C}$ virus infection. $\mathrm{J}$ Viral Hepat 9: 429-437, 2002.

19. Jolivet-Reynaud C, Adida A, Michel S, et al: Characterization of mimotopes mimicking an immunodominant conformational epitope on the hepatitis C virus NS3 helicase. J Med Virol 72: 385-395, 2004.

20. Kato T, Miyamoto M, Furusaka A, et al: Processing of hepatitis C virus core protein is regulated by its $\mathrm{C}$-terminal sequence. $\mathrm{J}$ Med Virol 69: 357-366, 2003.

21. Feucht HH, Zollner B, Polywka S and Laufs R: Study on reliability of commercially available hepatitis $C$ virus antibody tests. J Clin Microbiol 33: 620-624, 1995. 